\title{
Formation of Nano-Structured Materials via Coalescence of Amphiphilic Hollow Particles
}

\author{
Panya Sunintaboon, ${ }^{1}$ Kin Man Ho, ${ }^{2}$ Pei Li, ${ }^{2}$ Stephen Z. D. Cheng, ${ }^{1}$ Frank W. Harris* ${ }^{1}$ \\ ${ }^{1}$ Maurice Morton Institute and Department of Polymer Science, The University of Akron, \\ Akron, Ohio, 44325-3909 \\ ${ }^{2}$ Department of Applied Biology and Chemical Technology, The Hong Kong \\ Polytechnic University, Hung Hom, Kowloon, Hong Kong, P. R. China
}

\section{Experimental details}

\section{1) Synthesis of PMMA/PEI Core-Shell Particles}

Poly(ethyleneimine) (PEI) (2.0 g, $50 \mathrm{wt} \%$ aqueous solution, $M_{\mathrm{w}} 750,000 \mathrm{~g} / \mathrm{mol}$ ) was diluted with distilled water $(44 \mathrm{~mL})$ and mixed with purified methyl methacrylate (MMA) (4.0 g) in a water-jacketed flask equipped with a thermometer, a condenser, a magnetic stirrer, and a nitrogen inlet. The mixture was stirred and purged with nitrogen for $30 \mathrm{~min}$. After tert-butyl hydroperoxide (TBHP) $\left(0.625 \mathrm{~mL}, 1.0 \times 10^{-2} \mathrm{M}\right)$ was added, the mixture was stirred and heated at $80{ }^{\circ} \mathrm{C}$ for $2 \mathrm{~h}$ under nitrogen to produce stable colloidal PMMA/PEI particles. The monomer conversion was $>90 \%$.

The PMMA/PEI particles were purified by multiple centrifugations, decantations and rewetting cycles. An emulsion of the particles was then freeze-dried. The solid product was extracted with chloroform for $48 \mathrm{~h}$ using a Soxhlet extractor. The insoluble PEI-g-PMMA copolymer remained in the thimble, while the PMMA homopolymer was extracted into the chloroform. The FTIR spectrum of the copolymer contained strong 
absorptions at $1730 \mathrm{~cm}^{-1}$, characteristic of the PMMA carbonyl, and at $3400 \mathrm{~cm}^{-1}$, characteristic of the PEI amino groups (Figure S1).

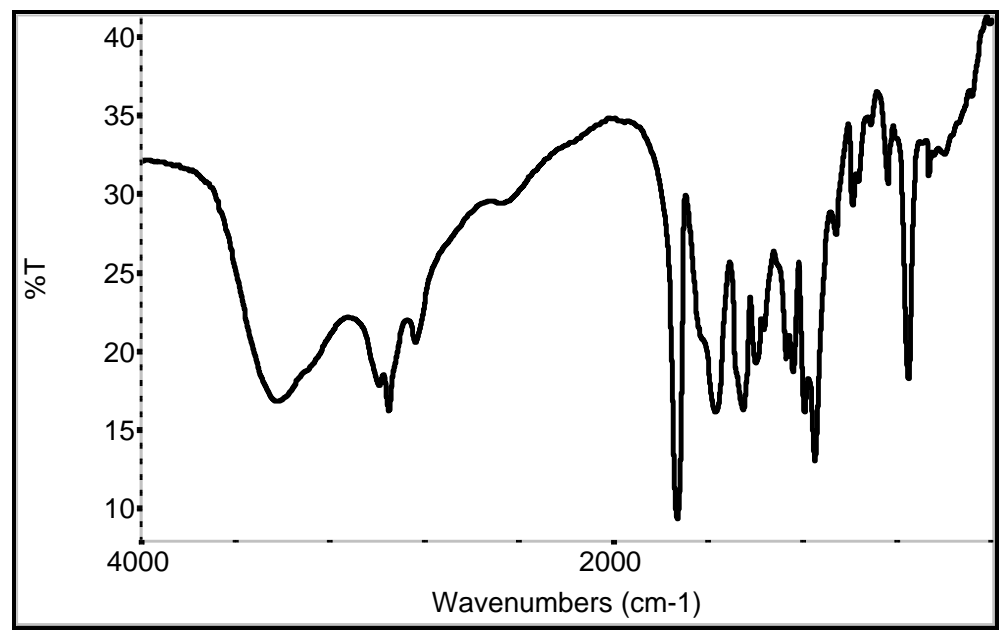

Figure S1. FTIR spectrum of the PEI-g-PMMA copolymer.

\section{2) Formation of hollow particles and nanotubes}

The freeze-dried PMMA/PEI powder $(0.5 \mathrm{~g})$ was stirred with $50 \mathrm{~mL}$ of $1 \%$ glutaraldehyde solution for $2 \mathrm{~h}$ at room temperature to slightly crosslink the shells via Shiff-base reactions of the PEI amino groups. The shell-crosslinked particles were purified by repeated washings with water and acetone and then freeze-dried. The FTIR spectrum of the crosslinked particles contained a weak absorption at $1650 \mathrm{~cm}^{-1}$, characteristic of an imine linkage (-C=N-).

The shell-crosslinked PMMA/PEI particles (0.5 g) were stirred in DCM (20 mL) for $3 \mathrm{~h}$ in order to extract the PMMA homopolymer. The viscosity of the solution increased considerably due to the dissolution of the PMMA. Water was then added and the heterogeneous mixture stirred. The aqueous phase was isolated, diluted with water, 
dried on a copper grid at room temperature, and the residual material was stained with a 2\% phosphotungstic acid (PTA) solution.

\section{3) Formation of microrods and microfibers}

The freeze-dried PMMA/PEI particles (0.1 g) were gently stirred (150 rpm) in DCM (4 mL) at room temperature for $3 \mathrm{~h}$ in order to extract the PMMA homopolymer. Water (9.3 $\mathrm{mL}$ ) was then added. The resulting DCM/water mixture was stirred at 150 or 350 rpm or sonicated (Branson 5510E-MT, 135W/42Hz) at room temperature in air. The DCM layer evaporated slowly during stirring. After complete removal of the DCM, the suspended white solids were collected by filtration and dried. FTIR spectra of the solid samples confirmed that they were PMMA homopolymers (Figure S2). The amount of PEI-g-PMMA copolymer, which remained in the water, was estimated according to following equation:

Graft copolymer in water $\%=\frac{\text { weight of particles added }- \text { weight of suspended solids }}{\text { weight of particles added }} \times 100 \%$ 


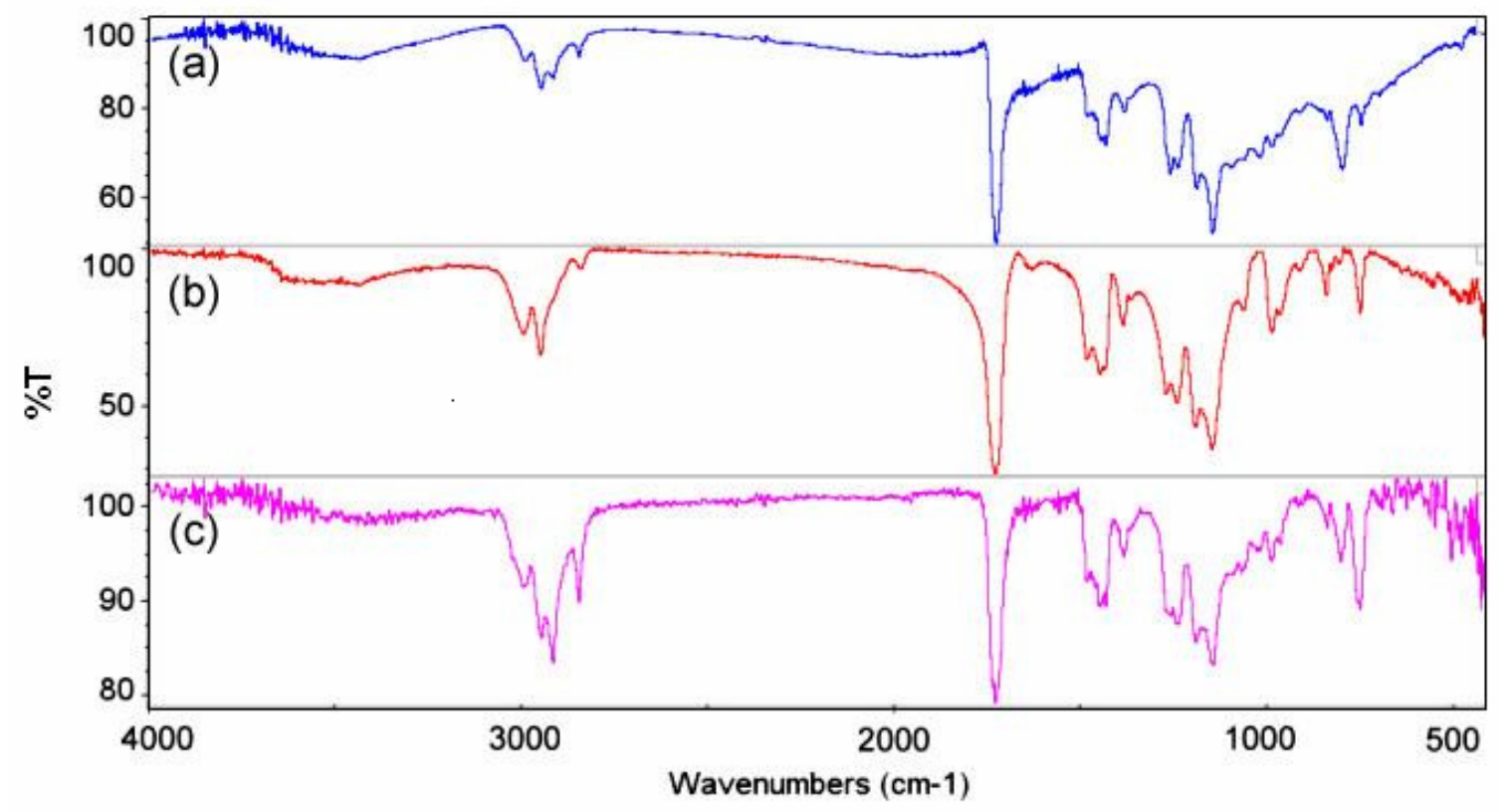

Figure S2. FTIR spectra of suspended solids (PMMA homopolymer) obtained by the slow evaporation of DCM from a water/DCM (70:30 v/v) mixture in air: (a) stirring at $150 \mathrm{rpm}$; (b) stirring at $350 \mathrm{rpm}$; (c) under ultrasonic treatment.
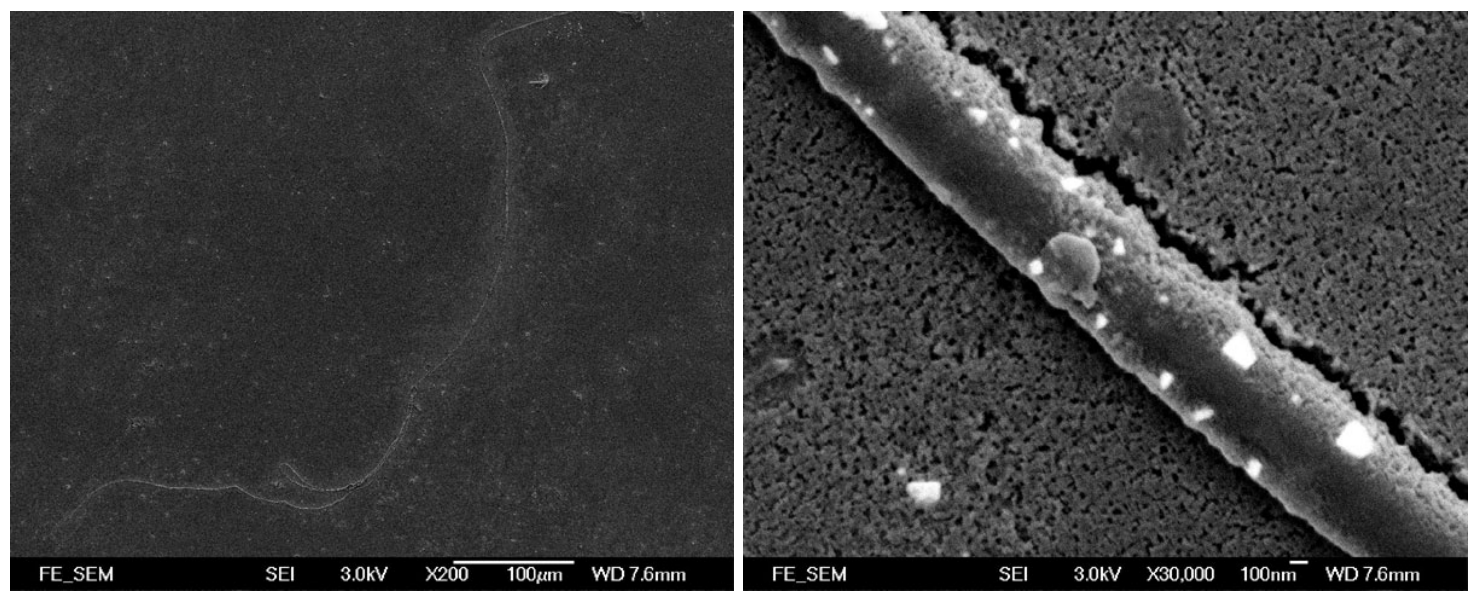

Figure S3. Field Emission Scanning Electron Microscopy (FE-SEM) images of PEI$g$-PMMA microfibers obtained in water via a slow evaporation of DCM from the water/DCM mixture (70:30 v/v) under stirring at $350 \mathrm{rpm}$ in air (graft copolymer in water $=50 \%$ ). (It is speculated that the white spots are absorbed PMMA homopolymer.) 

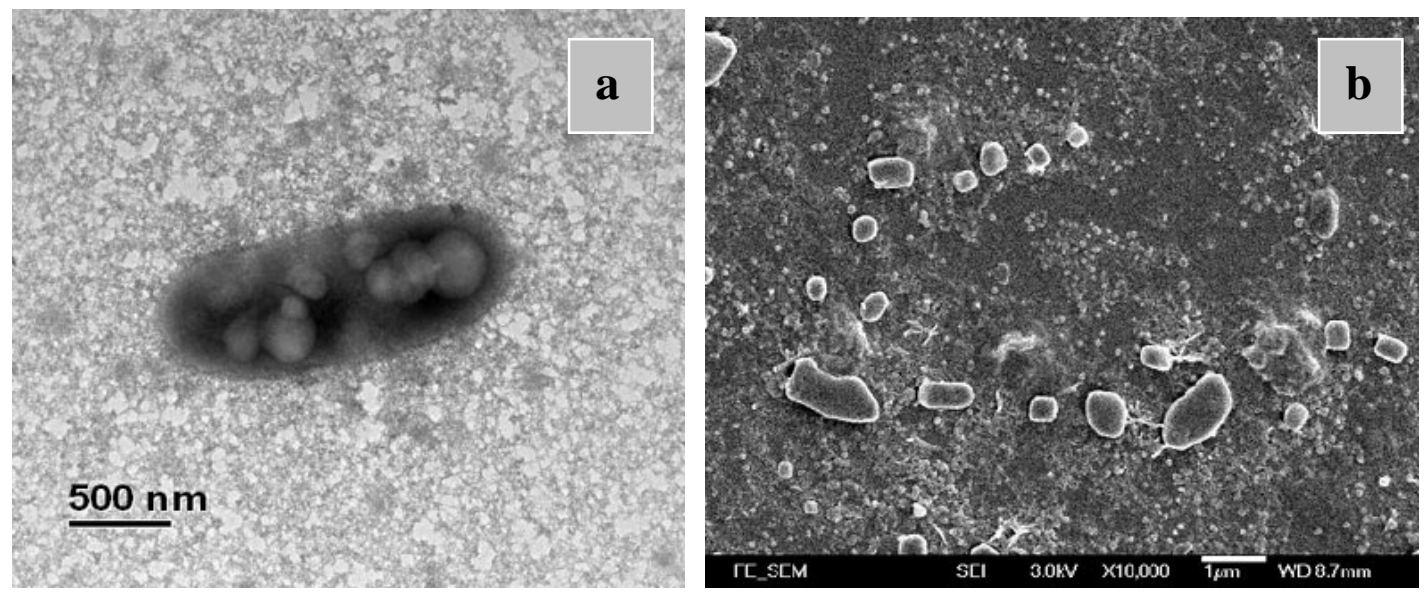

Figure S4. (a) TEM image of a microrod prepared by assembly of PEI-g-PMMA hollow particles via the slow evaporation of DCM from the water/DCM (70:30 v/v) mixture under ultrasound treatment (graft copolymer in water = 30\%). (b) FE-SEM image of the particles after treating the microrods with DCM.

Table 1. Summary of experimental conditions and their corresponding morphologies

\begin{tabular}{|c|c|c|c|c|}
\hline $\begin{array}{l}\text { Crosslinking } \\
\text { degree of the } \\
\text { PEI shell }\end{array}$ & $\begin{array}{l}\text { Solvent for } \\
\text { core } \\
\text { extraction }\end{array}$ & $\begin{array}{l}\text { Conditions to } \\
\text { induce } \\
\text { coalescence }\end{array}$ & $\begin{array}{l}\text { Types of observed } \\
\text { morphologies }\end{array}$ & $\begin{array}{l}\text { Diameter } \\
\text { range }\end{array}$ \\
\hline $1 \%^{a}$ & DCM & $\begin{array}{l}\text { Stirring the } \\
\text { heterogeneous } \\
\text { mixture }\end{array}$ & $\begin{array}{c}\text { Hollow PEI-g-PMMA } \\
\text { particles } \\
\text { Nanotubes } \\
\text { Worm-like nanotubes }\end{array}$ & $\begin{array}{c}160-210 \\
\mathrm{~nm} \\
60-100 \mathrm{~nm} \\
\sim 30 \mathrm{~nm}\end{array}$ \\
\hline $0 \%$ & DCM & $\begin{array}{l}\text { Evaporation of } \\
\text { DCM during } \\
\text { stirring at } 150 \\
\text { rpm }^{b}\end{array}$ & $\begin{array}{c}\text { Microrods (major) } \\
\text { Hollow PEI-g-PMMA } \\
\text { particles (minor) }\end{array}$ & $\begin{array}{c}0.45-0.6 \mu \\
\mathrm{m} \\
160-250 \\
\mathrm{~nm}\end{array}$ \\
\hline $0 \%$ & DCM & $\begin{array}{l}\text { Evaporation of } \\
\text { DCM during } \\
\text { stirring at } 350 \\
\text { rpm }^{b}\end{array}$ & Microfibers & $\sim 0.5 \mu \mathrm{m}$ \\
\hline $0 \%$ & DCM & $\begin{array}{l}\text { Evaporation of } \\
\text { DCM with } \\
\text { ultrasonic } \\
\text { treatment }^{b}\end{array}$ & Microrods & $\begin{array}{c}0.4-0.6 \mu \\
\mathrm{m}\end{array}$ \\
\hline
\end{tabular}

${ }^{a}$ Treating the PMMA/PEI particles with a $1 \%$ glutaraldehyde solution. ${ }^{b}$ Volume ratio of water to DCM is 70:30. 